\title{
A comparative assessment of endothelium from pseudophakic and phakic donor corneas stored in organ culture
}

\author{
F M Meier, S A Tschanz, R Ganzfried, D Epstein
}

See end of article for authors' affiliations

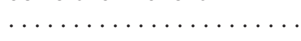

Correspondence to: Daniel Epstein, MD, PhD, Department of Ophthalmology, University Hospital, Fraven-

klinikstrasse 24, 8091

Zurich, Switzerland

Accepted for publication 31 October 2001

\begin{abstract}
Aims: To evaluate the endothelial quality of corneas obtained from pseudophakic donors and to compare the data with matched phakic controls.

Methods: Corneas from eyes with posterior chamber intraocular lenses (PCIOLs) and corneas from phakic eyes (controls) were stored for 1-2 weeks in organ culture and then examined after staining with Alizarin red S. The corneas were divided into two groups according to the duration of storage. Endothelial cell density, the percentage of hexagonal cells, and the coefficient of variation (CV) were determined.

Results: There was no statistically significant difference between the $14 \mathrm{PClOL}$ corneas and the 13 controls stored in organ culture for 7 days for any of the three parameters studied. The mean cell density was 2155 (SD 529) cells $/ \mathrm{mm}^{2}$ in the PCIOL corneas and 2118 (453) cells $/ \mathrm{mm}^{2}$ in the controls $(p=0.85)$. The mean percentage of hexagonal cells was $52 \%(8 \%)$ and $58 \%(7 \%)$, respectively $(p=0.06)$. The mean $C V$ was $0.32(0.18)$ in the pseudophakic corneas and $0.39(0.18)$ in the controls $(p=0.33)$. Moreover, there was no significant difference between the PCIOL corneas and the controls stored for up to 2 weeks.

Conclusions: The corneal endothelium from eyes with PCIOLs appears to be similar to that of phakic eyes after 1-2 weeks in organ culture. This finding suggests that corneas from pseudophakic eyes should not routinely be disqualified for transplantation. The use of at least some pseudophakic corneas may substantially increase the potential donor pool.
\end{abstract}

The chronic worldwide undersupply of donor corneas for keratoplasty has spawned a search for new sources of tissue. One such potential source, often untapped and sometimes scorned, is the very large pool of pseudophakic eyes. Corneas from such eyes have generally been disqualified as transplantation material on the assumption that the endothelium of an eye which had undergone anterior segment surgery would not meet keratoplasty criteria.

Very little has been published on the endothelium quality of pseudophakic corneas. ${ }^{1}$ We have therefore performed an in vitro study comparing the endothelium from pseudophakic corneas with that of corneas from phakic eyes. Cell density, the percentage of hexagonal cells, and the coefficient of variation of cell size were analysed. These parameters, which are generally used to define endothelial cell quality, display physiological changes with age. ${ }^{2}$ But they are also affected by disease (for example, acute glaucoma), contact lens wear, and anterior segment procedures. ${ }^{3}$

Endothelial cell damage due to cataract surgery is correlated with surgeon experience, the procedure chosen, the irrigating solutions and viscoelastics used, and the placement of the intraocular lens (IOL). Modern small incision techniques with very brief phacoemulsification times and in the bag IOLs have substantially reduced endothelial cell loss. ${ }^{4-10}$

\section{METHODS}

Corneas from donor eyes with a posterior chamber intraocular lens (PCIOL) and corneas from phakic donor eyes (controls) were stored in organ culture at $35.5^{\circ} \mathrm{C}$ for up to 2 weeks in an eye bank setting.

Donors with infectious or neoplastic disease as well as corneas with Fuchs' dystrophy or degenerative changes were excluded. There was no age limit for donors and no required minimum endothelial cell count.
The organ culture consisted of Eagle's minimal essential medium with Earle's salts, as well as $2 \%$ fetal calf serum and $1 \%$ antibiotic/antimycotic solution (GibcoBRL). Before analysis of the endothelial layer at the end of the storage period, the corneas were dehydrated for 1 day in a medium containing $6 \%$ high molecular dextran T500, to decrease stromal oedema. They were then stained with Alizarin red S.

A phase contrast microscope was used. With a Polaroid system and at 250× magnification, one image per cornea was captured at a random position in the central region of the endothelium. Each image covered an area of $622 \times 465 \mu \mathrm{m}$, that is, $0.289 \mathrm{~mm}^{2}$ with between 350 and 1250 cells. The images were printed on paper $(186 \times 249 \mathrm{~mm})$ with a monochrome laser printer.

A prestudy pilot showed that photographs of unstained endothelium had a much poorer resolution than those stained with Alizarin red S. Accordingly, accurate cell counts were practically impossible to perform and cell borders very difficult to ascertain in unstained corneas. For this reason, no prestorage endothelial evaluation of the corneas used in this study was done.

Forty seven corneas from 34 donors were studied. Twenty six corneas were obtained from eyes with PCIOLs and 21 from phakic (control) eyes. Two donors each contributed one eye to the PCIOL group and one eye to the control group. The PCIOL group and the control group were each further subdivided into two subgroups, depending on the duration of storage. Twenty seven corneas ( 14 from PCIOL eyes and 13 from control eyes) were stored for 1 week in organ culture (group A). Twenty corneas ( 12 PCIOL and eight controls) were stored for 10-14 days (mean 13 days), and were designated as group B.

The following parameters were studied, using morphometric techniques: endothelial cell density (a), the number of adjacent cells, a measure for hexagonality (b), the number 


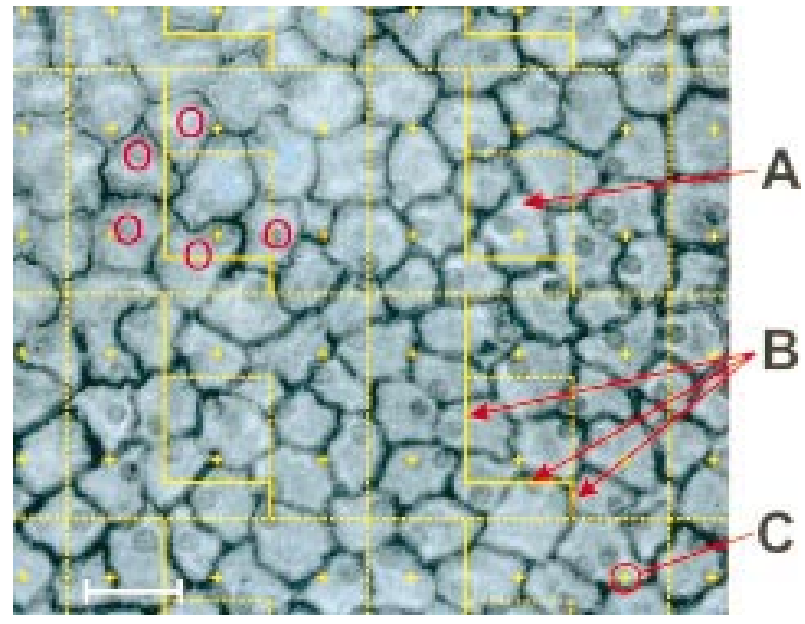

Figure 1 Detail of a cornea culture image with an overlaid test system. (A) Subsampling square. (B) "Forbidden lines." (C) Test points of the second test grid for the detection of fuzzy image regions (see text). As an example, red circles indicate not counted cells, yellow crosses indicate cells which are counted within this particular subsampling square. White bar $=50 \mu \mathrm{m}$.

weighted mean cell area (c), the area weighted mean cell area calculated from point sampled intercepts (d), and the coefficient of variation of cell size (e). All measurements were performed two dimensionally since the endothelial layer represents planar structures.

These five parameters were measured as follows.

\section{Cell density}

Cell density $\left(\mathrm{N}_{\mathrm{a}}\right)$ was calculated as the number of cells per $\mathrm{mm}^{2}$. This number was estimated by using a subsampling procedure taking into account the edge effect. ${ }^{11}{ }^{12}$ Briefly, a transparent overlay divided into squares was superimposed on each image. It was used to sample one sixth of the image area ( $\mathrm{A}$ in Fig 1). The lower left border as well as the vertical "appendages" (solid lines B in Fig 1) were defined as off-limit lines. All cells located within the squares and not touching the off-limit lines were counted.

Areas in which cell borders were not clearly visible were also sampled. In addition to the squares, the transparent overlay contained a point grid test system (points C in Fig 1). Points overlying such out of focus areas were counted. The ratio between these points and all test points yielded a coefficient, which was used to correct the overall cell density measurement so as to take account of the out of focus areas.

\section{Adjacent cells}

The number of adjacent cells was determined for every cell sampled in the cell density measurement. The generally hexagonal arrangement of the normal endothelium shifts during storage owing to cell death and cell size changes, so that the number of adjacent cells varied between four and eight.

\section{Number weighted mean cell area}

The number weighted mean cell area $\left(\bar{a}_{N}\right)$ was calculated by dividing the whole image area by the total number of cells per image.

\section{Area weighted mean cell area}

The area weighted mean cell area $\left(\bar{a}_{A}\right)$ was computed by the point sampled intercept method. ${ }^{13}$ This mean area calculation is based on the number of cells sampled proportional to their area surface size. Larger cells weigh proportionally heavier in this parameter. A test grid with parallel lines and with equidistant rulers bisecting these lines was superimposed on each endothelium photograph in a random orientation (Fig

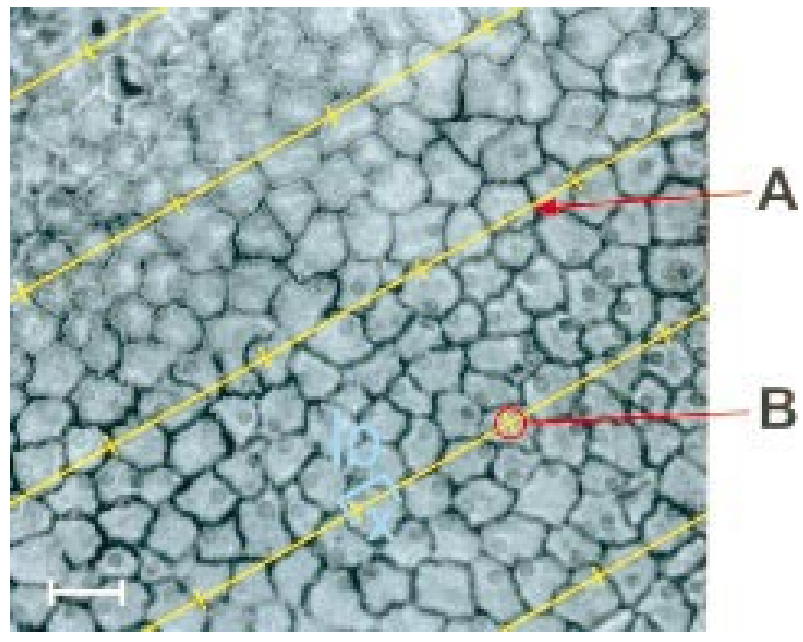

Figure 2 Detail of a culture image with an overlaid grid for point sampled intercept measurement. (A) Test lines. (B) Sampling rulers. Yellow cross indicates a sampled cell. Yellow ruler corresponds to the intercept length $\lambda_{\circ}$ of this cell. White bar $=50 \mu \mathrm{m}$

2). The points at which the rulers bisected the parallel lines were used as sampling points. For each sampling point that hit a cell, the length of the intercept within the cell was measured along the test line. The test grid was then rotated five times, each time by $30^{\circ}$, and the measurement repeated every time. On average about 100 cells were sampled. An unbiased estimator of $\left(\bar{a}_{A}\right)$ is

$$
\hat{\bar{a}}_{A}=\frac{\pi}{3} \cdot \frac{\left(\lambda_{01}^{2}+\lambda_{02}^{2}+\ldots+\lambda_{0 m}^{2}\right)}{m}
$$

where $\lambda_{o i}$ is the length of the $i$ th intercept and $m$ the number of sampled cells.

\section{Coefficient of variation}

The coefficient of variation of cell area reflects the variation of cell size within the endothelial layer of a single cornea, as documented by each endothelial photograph. It corresponds to the standard deviation of individual cell areas divided by the mean cell area. If $\bar{a}_{A}$ and $\bar{a}_{N}$ are known, the coefficient of variation is

$$
C V_{N}(a)=\sqrt{\left(\bar{a}_{A} / \bar{a}_{N}\right)-1}
$$

The unpaired, two tailed Student's $t$ test was used for statistical analysis.

Statistical significance was defined as $\mathrm{p}<0.05$.

\section{RESULTS}

The PCIOL corneas and the phakic (control) corneas matched for age, time from death to enucleation, and time from enucleation to storage in both group A and group B, except that the mean age of the controls in group B was significantly lower $(\mathrm{p}<0.001)$. Details of these data and sex distribution are shown in Table 1.

There were no statistically significant differences between the PCIOL corneas and the controls for any of the three major endothelial parameters (cell density, percentage of hexagonal cells, and coefficient of variation) studied (Table 2).

The mean cell densities were 2155 (SD 529) cells $/ \mathrm{mm}^{2}$ for the PCIOL corneas and 2118 (453) cells $/ \mathrm{mm}^{2}$ for the controls in group A $(\mathrm{p}=0.85)$, and 1922 (391) cells $/ \mathrm{mm}^{2}$ and 2205 (579) cells $/ \mathrm{mm}^{2}$, respectively, in group $B(p=0.21)$. The mean 
Table 1 Donor corneas

\begin{tabular}{llllll}
\hline & \multicolumn{2}{l}{ Group A } & & \multicolumn{2}{l}{ Group B } \\
\cline { 2 - 3 } \cline { 5 - 6 } \cline { 5 - 6 } & PCIOL & Control & & PCIOL & Control \\
\hline Number & 14 & 13 & & 12 & 8 \\
Sex & & & & & \\
$\quad$ Female & 6 & 9 & & 7 & 3 \\
$\quad$ Male & 83 & 78 & & 5 & 5 \\
Age (years) & 8 & 13 & & 8 & 61 \\
SD & 12.6 & 12.3 & & 14.9 & 13.5 \\
DTET (hours) & 6.3 & 9.2 & & 5.7 & 7.7 \\
SD & 1.8 & 2.4 & & 1.8 & 2.2 \\
ETPT (hours) & 1.3 & 1.3 & & 1.0 & 0.8 \\
SD & 7 & 7 & & 13 & 13 \\
Culture time (days) & 7 & 0 & 0 & 2 & 2 \\
SD & 0 & & & &
\end{tabular}

DTET = time from death to enucleation, ETPT = time from enucleation to preservation, $\mathrm{SD}=$ standard deviation.

percentage of hexagonal cells was 52 (8) for the PCIOL eyes and 58 (7) for the controls in group A $(p=0.06)$, and 53 (7) versus $54(6)$ in group $B(p=0.72)$. The corresponding mean coefficient of variation values were $0.32(0.18)$ and $0.39(0.18)$ in group $A(p=0.33)$, and $0.25(0.09)$ versus $0.25(0.14)$ in group $B(p=0.96)$.

Eight of the 14 pseudophakic corneas and eight of the 13 controls in group A had cell counts over 2000, and would therefore have qualified as donor corneas for keratoplasty. In group B four corneas of 12 pseudophakic eyes and five of eight controls had a cell density higher than 2000 cells $/ \mathrm{mm}^{2}$.

The incidence of polymegethism (coefficient of variation $>0.3$ ) was also analysed. Seven of the 14 pseudophakic donors and in four of the 13 controls in group A, and eight of 12 pseudophakes and six of eight controls in group B showed no polymegethism. In group A there were four pseudophakic corneas and two controls, and in group B two pseudophakes and four controls manifesting both attractive quality markers-that is, cells counts over 2000 and the absence of polymegethism (Table 3 ).

\section{DISCUSSION}

Modern cataract surgery and, especially, the use of small incisions, extremely short phacoemulsification times and in the bag PCIOLs have substantially reduced intraoperative endothelial layer damage and subsequent cell loss. ${ }^{6-10}$

These advances in the most frequently performed intraocular anterior segment procedure call into question previous assumptions made about the quality of donor corneas from pseudophakic eyes.

Although we were unable to identify the surgeons who operated on the pseudophakic donor eyes we used, and thus could not collect data on the type of procedure or when surgery was performed, it is reasonable to assume that not all of the pseudophakic eyes had undergone small incision phacoemulsification and that some of the cataracts were extracted with the more traumatic extracapsular technique.

Yet this study shows that there were no statistically significant differences between the endothelium of PCIOL corneas and phakic controls when comparing cell density, the percentage of hexagonal cells, and the coefficient of variation of cell area. These are the three most important morphological parameters used to assess endothelial quality. And although eye banks routinely use only cell density to determine the suitability of a cornea for keratoplasty, the fact that mean hexagonality and the mean coefficient of variation in this study were also comparable to phakic controls essentially strengthens the argument that corneas from pseudophakic eyes should generally not be rejected as potential donors.

Admittedly, even if only cell density was considered, not all of the pseudophakic corneas evaluated in this study would have qualified as donors. But also the phakic control group included inferior quality tissue-that is, corneas with less than 2000 cells $/ \mathrm{mm}^{2}$. With $57 \%(8 / 14)$ of the pseudophakic corneas stored for 1 week, and 33\% (4/12) of those stored for a mean of 13 days displaying cell counts higher than 2000, it is clear that rejecting pseudophakic donors out of hand is not justified. The fact that $50 \%(7 / 14)$ of the pseudophakes stored for 1 week and $67 \%(8 / 12)$ in the longer storage group showed no polymegethism (coefficient of variation <0.3) further underscores the importance of considering pseudophakic eyes as possible donors.

\begin{tabular}{|c|c|c|c|c|}
\hline & \multicolumn{2}{|l|}{ Group A } & \multicolumn{2}{|l|}{ Group B } \\
\hline & $\mathrm{PCIOL}$ & Control & $\mathrm{PCIOL}$ & Control \\
\hline Cells $/ \mathrm{mm}^{2}$ & 2155 & 2118 & 1922 & 2205 \\
\hline SD & 529 & 453 & 391 & 579 \\
\hline Range & $1412-3584$ & $1417-2842$ & $1416-2380$ & 1520-3095 \\
\hline Hexagonal cells & $52 \%$ & $58 \%$ & $53 \%$ & $54 \%$ \\
\hline SD & $8 \%$ & $7 \%$ & $7 \%$ & $6 \%$ \\
\hline Range & $38-65 \%$ & $43-69 \%$ & $41-62 \%$ & $47-63 \%$ \\
\hline Coefficient of variation & 0.32 & 0.39 & 0.25 & 0.25 \\
\hline SD & 0.18 & 0.18 & 0.09 & 0.14 \\
\hline Range & $0.06-0.42$ & $0.1-0.75$ & $0.08-0.36$ & $0.12-0.56$ \\
\hline
\end{tabular}

\begin{tabular}{|c|c|c|c|c|}
\hline & \multicolumn{2}{|l|}{ Group A } & \multicolumn{2}{|l|}{ Group B } \\
\hline & $\mathrm{PCIOL}$ & Control & $\mathrm{PCIOL}$ & Control \\
\hline $\begin{array}{l}\text { Cell density }>2000 / \mathrm{mm}^{2} \\
\text { Coefficient of variation }<0.3 \\
\text { Cell density }>2000 / \mathrm{mm}^{2}+\text { coefficient }\end{array}$ & $\begin{array}{l}8 / 14(57 \%) \\
7 / 14(50 \%)\end{array}$ & $\begin{array}{l}8 / 13(62 \%) \\
4 / 13(31 \%)\end{array}$ & $\begin{array}{l}4 / 12(33 \%) \\
8 / 12(67 \%)\end{array}$ & $\begin{array}{l}5 / 8(63 \%) \\
6 / 8(75 \%)\end{array}$ \\
\hline of variation $<0.3$ & $4 / 14(29 \%)$ & $2 / 13(15 \%)$ & $2 / 12(17 \%)$ & $4 / 8(50 \%)$ \\
\hline
\end{tabular}


Because it is safe to assume that surgeon quality will never become uniform and that islands of old fashioned surgical techniques will persist, pseudophakic donor eyes can be expected to manifest both high quality and low quality corneas. But the results of our study indicate that this will probably not make them much different from phakic eyes routinely harvested by eye banks. The process of evaluation performed by eye banks should be sufficient to disqualify poor quality pseudophakic corneas in the same way it excludes poor quality phakic corneas.

Johnston et al published a similar study, but had used freshly enucleated donor eyes with IOLs (14 PCIOLs and one ACIOL) which they compared with matched controls. ${ }^{1}$ Also the Johnston study, which in addition to cell density analysed hexagonality and the coefficient of variation, found no significant differences in endothelium quality between the two groups.

Compared to the present study, Johnston et al's corneas had a higher mean cell density in both the IOL and the control group ( 2495 cells $/ \mathrm{mm}^{2}$ and 2576 cells $/ \mathrm{mm}^{2}$, respectively). They also reported a higher percentage of corneas with cell counts over 2000. This may be due to the higher mean donor age in the present study and to endothelial cell loss which occurs during organ culture storage. The percentage of hexagonal cells and the coefficient of variation were comparable in both studies.

The present study specifically aimed at endothelial assessment after 1-2 weeks in organ culture because this storage method has some major advantages over short term storage at $4^{\circ} \mathrm{C}$. Storage time is significantly longer, which facilitates the scheduling of keratoplasties and reduces donor tissue wastage. The extended storage time also makes the matching of typed corneas easier. It further makes it possible to evaluate the endothelium immediately before surgery. And there appears to be no difference in the clinical outcome of keratoplasties when corneas from the two different storage systems are compared. ${ }^{14-16}$

The fact that prestorage endothelial assessment was not performed does not detract from the results obtained, since the purpose of the study was to analyse the quality of the endothelium before potential use, and not to determine how that quality may have decreased during organ culture.

Because cell loss from cataract surgery can take quite a while to equilibrate across the entire endothelium, ${ }^{6}$ a central cell count by an eye bank may not reveal a severe deficiency due to peripheral damage. Accordingly, it is probably advisable, when harvesting tissue from pseudophakic donors, to use only eyes with at least one year since surgery.

Caution should also be exercised in view of the increasing number of refractive procedures being performed. A pseudophakic eye which had also undergone an excimer ablation (possibly with a laser in situ keratomileusis flap), should probably also be excluded, at the very least because such a cornea may be difficult to handle.

The chronic worldwide shortage of donor corneas puts increasing pressure on eye banks to find new sources of tissue. As life expectancy increases more people develop cataracts and more cataract surgery is performed. It is therefore likely that eye banks will find themselves dealing with an increasing number of pseudophakic eyes. As this pilot study indicates (and as a larger multicentre project could confirm), the acceptance of pseudophakic eyes by eye banks would substantially increase the donor pool. Alternatively, the routine disqualification of pseudophakic corneas would deprive eye banks of potential donor tissue. The fact that potential pseudophakic donors may be older than phakic ones should not automatically exclude them from being considered..$^{17}$

\section{ACKNOWLEDGEMENTS}

We wish to express our gratitude to Farhad Hafezi, MD, and Pascal Rol, $\mathrm{PhD}$, for sharing generously their knowledge and letting us use their computers and the optical equipment.

We deeply regret the loss of Pascal Rol, who died tragically in January 2000. He was not only an excellent optical physicist but also a caring colleague and his dedication and kindness will always be remembered.

\section{Authors' affiliations}

F M Meier, R Ganzfried, D Epstein, Department of Ophthalmology, University Hospital Zurich, 8091 Zurich, Switzerland

S A Tschanz, Institute of Anatomy, University of Berne, 3000 Berne 9, Switzerland

\section{REFERENCES}

1 Johnston RH, Hasany S, Rootman DS. Endothelial cell analysis of corneas from donor eyes with an intraocular lens:a comparative study. Cornea 1997:16:531-3.

2 Yee RW, Matsuda M, Schultz RO, et al. Changes in the normal corneal endothelial cell pattern as a function of age. Curr Eye Res 1985;4:671-7.

3 Waring GO III, Bourne WM, Edelhauser HF, et al. The corneal endothelium. Ophthalmology 1989:89:531-90.

4 Binder PS, Sternberg H, Wickham MG, et al. Corneal endothelial damage associated with phacoemulsification. Am J Ophthalmol 1976;82:48-54.

5 Liesegang TJ, Bourne WM, Ilstrup DM. Short-and long-term endothelial cell loss associated with cataract extraction and intraocular lens implantation. Am J Ophthalmol 1984;97:32-9.

6 Schultz RO, Glasser DB, Matsuda M, et al. Response of the corneal endothelium to cataract surgery. Arch Ophthalmol 1986;104:1 164-9.

7 Lavery KT, McDermott ML, Ernest PH, et al. Endothelial cell loss after 4 mm cataract surgery. J Cataract Refract Surg 1995:21:305-8.

8 Matsuda M, Miyake K, Inaba M. Long-term corneal endothelial changes after intraocular lens implantation. Am J Ophthalmol 1988;105:248-52.

9 Ravalico G, Tognetto D, Baccara F, et al. Corneal endothelial protection by different viscoelastics during phacoemulsification. J Cataract Refract Surg 1997:23:433-9.

10 Werblin TP. Long-term endothelial cell loss following phacoemulsifiacation: model for evaluating endothelial damage after intraocular surgery. Refract Corneal Surg 1993;9:29-35.

11 Gundersen HJG. Notes on the estimation of the numerical density of arbitrary profiles: the edge effect. J Microsc 1977;111:219-23.

12 Gundersen HJG, Bendtsen TF, Korbo L, et al. Some new, simple and efficient stereological methods and their use in pathological research and diagnosis. APMIS 1988;96:379-94.

13 Gundersen HJG, Bagger P, Bendtsen TF, et al. The new stereological tool: dissector, fractionator, nucleator and point sampled intercepts and their use in pathological research and diagnosis. APMIS 1988;96:857-81

14 Hagenah $M$, Carstens $D$, Böhnke $M$, et al. Entwicklung der Endothelzelldichte bei Verwendung von frischem und organkultiviertem Gewebe. Ophthalmologe 1997:94:90-3.

15 Rijneveld WJ, Beekhuis WH, van Rij G, et al. Clinical comparison of grafts stored in McCarey-Kaufman medium at $4^{\circ} \mathrm{C}$ and corneal organ culture at $31^{\circ} \mathrm{C}$. Arch Ophthalmol 1992;110:203-5.

16 Redmond RM, Armitage WJ, Whittle J, et al. Long-term survival of endothelium following transplantation of corneas stored by organ culture. BrJ Ophthalmol 1992;76:497-81.

17 Armitage WJ, Easty DL. Factors influencing the suitability of organ-cultured corneas for transplantation. Invest Ophthalmol Vis Sci 1997;38:16-24. 